\title{
AUTO-ENXERTO PERCUTÂNEO DE MEDULA ÓSSEA EM COELHOS. I. COLETA, PREPARO E APLICAÇÃO ${ }^{1}$
}

\author{
PERCUTANEOUS BONE MARROW AUTOGRAFT IN RABBITS I. HARVESTING, \\ PROCESSING AND GRAFTING
}

\author{
Séfora Vieira da Silva Gouvea de Barros ${ }^{2}$ Ricardo Junqueira Del Carlo ${ }^{3}$ Marlene Isabel Vargas ${ }^{4}$ \\ Simone Rezende Galvão ${ }^{5}$ Alfredo Maia Filho ${ }^{5}$
}

\section{RESUMO}

Foram utilizados 36 coelhos da raça Nova Zelândia Branca, machos, com peso médio de $3,5 \mathrm{~kg}$ e idade entre cinco e seis meses para avaliação da coleta, do preparo e da técnica de aplicação do auto-enxerto percutâneo de medula óssea (MO). Em 20 coelhos anestesiados, uma agulha para punção de MO foi inserida na crista ilíaca, sendo a medula aspirada com auxílio de seringa de $20 \mathrm{~m} \ell$ heparinizada. As 20 amostras obtidas foram preparadas de duas maneiras, utilizando-se 10 amostras em cada procedimento: 1) medula integral: após a coleta de $1 m \ell, a$ amostra foi homogeneizada e, em casos de presença de coágulo, ela foi descartada; 2) medula centrifugada: após a coleta de $2 m \ell$ a medula foi centrifugada por 10 minutos, sendo o sobrenadante removido e $1 m \ell$ do sedimento homogeneizado. Em ambos os procedimentos, as amostras foram submetidas à contagem de células nucleadas. Nos 16 coelhos restantes, para permitir a avaliação da técnica de aplicação da MO, foi criada, cirurgicamente, uma falha óssea em ambos os rádios, pela remoção de um segmento osteoperiosteal com $1,0 \mathrm{~cm}$ de comprimento, localizado a três centímetros da articulação rádiocarpo-ulnar. Após cinco dias da realização das falhas ósseas, os 16 coelhos foram separados em dois grupos iguais (I e II), sendo novamente anestesiados e preparados para a enxertia. No grupo

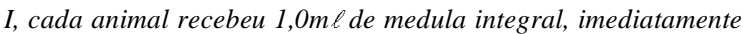

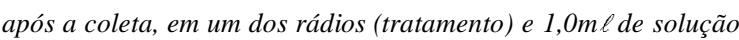
salina fisiológica no rádio contralateral (controle). No grupo II,

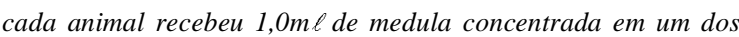

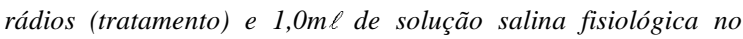
rádio contralateral (controle). Em função da característica física da medula, a coleta das amostras constituiu-se em procedimento simples, envolvendo trauma mínimo. Foi necessária prévia heparinização da seringa de coleta, o que não impediu a osteogenicidade das células. Com relação ao preparo das amostras, observou-se ampla variação individual na contagem celular nos dois procedimentos. A concentração da medula por centrifugação não interferiu negativamente no seu potencial osteogênico. A aplicação por via percutânea mostrou-se um método simples, com mínimo trauma aos tecidos, não introduzindo tecido desvitalizado e, desta forma, reduzindo o risco de infecção e de interferência na reparação óssea. A avaliação radiográfica dos membros operados, realizadas no dia da enxertia e uma semana após, demonstrou a eficiência da aplicação da MO e sua atuação na formação de osso.

Palavras-chave: cirurgia óssea, enxerto ósseo, reparação óssea.

\section{SUMMARY}

Thirty six White New Zealand male rabbits, that weighed $3.5 \mathrm{~kg}$, aged between 5 and 6 months were used for studying the harvesting, processing and percutaneous administration of bone marrow autograft. In 20 anesthetized rabbits, a needle for bone marrow collection was inserted in the iliac crest and marrow was aspirated with a $20 \mathrm{ml}$ heparinized syringe. The 20 samples were processed in 2 ways, 10 samples each way: 1) whole marrow: after 1-ml-harvest the sample was homogenized and in the case of coagulation, the sample was discarded; 2) centrifuged marrow: after 2-ml-harvest, the marrow was centrifuged for 10 minutes, then the supernatant was discarded and $1 \mathrm{~m} \ell$ of the sediment was homogenized. In both proceedings the samples were submitted to nucleated cell count. In order to evaluate the percutaneous administration of the bone marrow, in the 16 remaining rabbits an 1-cm osteal-periosteal segmental osteotomy in both radii was produced. Five days after

\footnotetext{
${ }^{1}$ Apoio financeiro FAPEMIG.

${ }^{2}$ Médico Veterinário, Professor Assistente, Centro Superior de Vila Velha, Universidade de Vila Velha, ES.

${ }^{3}$ Médico Veterinário, Professor Titular, Departamento de Veterinária, Universidade Federal de Viçosa (UFV), 36.570.000 Viçosa. E-

mail: ricarlo@mail.ufv.br. Autor para correspondência.

${ }^{4}$ Médico Veterinário, Professora Adjunta, UFV, MG.

${ }^{5}$ Médico Veterinário, UFV, MG.
} 
surgery, the 16 rabbits were set apart in groups I and II, anesthetized and prepared for grafting. Each animal of group I received $1.0 \mathrm{~m} \ell$ of whole bone marrow in one radius (treatment), immediately after harvesting and $1.0 m \ell$ of physiological saline in the contralateral radius (control). In group II each animal received 1.0 of concentrated marrow in one radius (treatment) and $1.0 \mathrm{~m} \ell$ of physiological saline solution in the contralateral radius (control). Because of the physical characteristics of medulla, its harvesting was a simple proceeding with minimal trauma. It was necessary to heparinize the syringe, there was no damage to the osteogenic potential of the samples. In relation to sample processing, it was observed wide individual variation of the cellular count in both proceedings. Medullary concentration did not negatively interfere on the osteogenic potential. Percutaneous marrow grafting was a simple method, with no need of surgical approach and no introducing of devitalized tissue, reducing this way risk of infection and interference of bone repair. Radiographic evaluation of the operated limbs demonstrated bone marrow grafting effectiveness in osseous formation.

Key words: bone surgery, bone graft, bone repair

\section{INTRODUÇÃO}

A medula óssea é constituída pelas células primordiais indiferenciadas, as stem cells (BURWELL, 1985), caracterizadas por baixa taxa de crescimento, capacidade de auto-renovação e potencial para diferenciarem-se em várias linhagens (OWEN, 1980; CONNOLLY, 1995). No processo de reparação óssea, células presentes na medula desempenham papel importante na osteogênese ou fagocitose, dependendo das condições do meio (BURWELL, 1985).

ASHTON et al. (1984) concluíram que células precursoras osteogênicas, apesar de encontradas por toda a medula, estão mais concentradas próximo à superfície endosteal. Eles observaram índices osteogênicos significativamente menores na população central. Para MUSCHLER et al. (1997), houve um aumento no número de células nucleadas quando o local de coleta da medula era altamente celular e as trabéculas ósseas estavam dispostas mais espaçadamente, permitindo que as células da cavidade medular fluíssem para a agulha de aspiração.

A importância das stem cells para a reconstituição óssea e sua quantidade relativamente pequena em relação às células nucleadas da medula (1:100.000) tem direcionado as pesquisas para seu isolamento, purificação e concentração (CONNOLLY, 1995). Elas estão distribuídas de maneira esparsa na medula (TIEDEMAN $\boldsymbol{e t}$ al., 1991) e métodos que tornem possível concentrar a população de células osteoprogenitoras podem favorecer a osteogênese, uma vez que a formação óssea está diretamente relacionada ao número de stem cells (CONNOLLY et al.,1989).
A técnica de injeção de MO via percutânea é relativamente simples, de custo moderado e minimiza as complicações advindas da imobilização prolongada do membro (CONNOLLY et al., 1989; CONNOLLY, 1995). Segundo GARG et al. (1993), esse procedimento determina trauma mínimo, evita intercorrências no sítio receptor e pode ser repetido facilmente.

Segundo CONNOLLY et al. (1991), a crista ilíaca é a melhor fonte de MO; e para SALAMA \& WEISSMAN (1978) ela pode ser obtida através de agulha de biópsia por aspirações sucessivas, em vários pontos espaçados de $1 \mathrm{a} 2 \mathrm{~cm}$. São obtidas pequenas quantidades em cada aspiração, prevenindo a diluição dos elementos da medula com sangue aspirado (SALAMA, 1983; GARG et al., 1993; CONNOLLY, 1995).

Para TIEDEMAN et al. (1991), entre as aspirações, a agulha e a seringa devem ser lavadas com $4 \mathrm{~m} \ell$ de solução salina heparinizada, para evitar formação de coágulo. SALAMA \& WEISSMAN (1978) constataram que a heparina determinou alterações nas propriedades tintoriais das células, sugestivas de dano celular. Já, HEALEY et al. (1990), consideraram desnecessário heparinizar a seringa durante a aspiração e injeção, devido ao curto intervalo de tempo entre os procedimentos.

Em um estudo, a MO foi aspirada da crista ilíaca de coelhos adultos anestesiados, através de agulha hipodérmica que foi rotacionada cuidadosamente, acoplada a uma seringa de $20 \mathrm{~m} \ell$ umedecida com solução de heparina (1:1000). Foram coletados 2,0 a $3,0 \mathrm{~m} \ell$ por sítio, até um total de 7,0 a $10 \mathrm{~m} \ell$ por animal (CONNOLLY et al., 1989). Já PALEY et al. (1986) coletaram a MO do trocanter maior de coelhos impúberes $2,0 \mathrm{~m} \ell$, utilizando uma agulha espinhal.

Segundo PALEY et al. (1986) e CONNOLLY et al. (1991), simultaneamente com a aspiração da medula, uma segunda agulha deve ser inserida no local de enxertia, permitindo sua aplicação imediata. Desta forma, é mantido um maior número de células viáveis. Para CONNOLLY et al. (1991) a MO pode ser depositada no sítio receptor por injeção percutânea e, naqueles casos em que a redução aberta for necessária para remoção de implantes, a medula coagulada pode ser aplicada. LOKIEC et al. (1996) não recomendaram sua aplicação percutânea, quando coagulada.

PALEY et al. (1986) concluíram que a enxertia percutânea de MO não deve ser realizada no dia da intervenção cirúrgica. SHARMA et al. (1992), igualmente, recomendaram a aplicação após 5 dias, permitindo a cicatrização da ferida. Em outro 
estudo, CONNOLLY (1995) constatou que o momento ideal para injeção percutânea deve ser após a redução da inflamação inicial e do período de reabsorção osteoclástica, que ocorreu entre 6 a 12 semanas, em humanos. O autor considera que $\mathrm{o}$ efeito osteogênico inicia-se imediatamente após a enxertia.

Fragmentos ósseos reimplantados foram associados à enxerto de MO autógena, promovendo união em fraturas cominutivas de tíbia e fêmur de pacientes humanos. Quando a ferida não estava suficientemente cicatrizada no tratamento inicial, a enxertia foi feita após quatro a seis semanas, período no qual não havia inflamação (CONNOLLY, 1998).

Segundo PALEY et al. (1986) e CONNOLLY (1995) a medula óssea autógena, em casos clínicos e experimentais de não união, tende a se difundir ao redor do local da fratura, existindo um risco potencial de formação ectópica de osso.

Reconhecido o potencial da MO em enxertias, o presente estudo teve por objetivos avaliar o número de células nucleadas que podem ser obtidas por aspirado, a possibilidade de concentração por centrifugação antes da enxertia, e detalhes da técnica de aplicação percutânea de medula no rádio de coelhos.

\section{MATERIAL E MÉTODOS}

O experimento foi conduzido no Departamento de Veterinária da Universidade Federal de Viçosa, em 36 coelhos da raça Nova Zelândia Branca, machos, com peso médio de $3,5 \mathrm{~kg}$ e idade entre cinco e seis meses. O protocolo anestésico consistiu de medicação pré-anestésica com acepromazina ${ }^{\mathrm{a}}(0,2 \mathrm{mg} / \mathrm{kg}$ IV) e anestesia com tiletamina/zolazepan $^{\mathrm{b}} \quad(15 \mathrm{mg} / \mathrm{kg} \quad \mathrm{IV})$. Em cada coelho, foi aplicado $40.000 \mathrm{UI} / \mathrm{kg}$ via IM de penicilina benzatina ${ }^{c}$, no momento da medicação pré-anestésica. Após a cirurgia, os animais foram alojados em gaiolas individuais onde receberam ração comercial ${ }^{\mathrm{d}}$ e água ad libitum. Cada coelho recebeu identificação individual na face interna da orelha.

Em 20 coelhos anestesiados, uma agulha para punção de medula óssea ${ }^{\mathrm{e}}$ foi inserida na crista ilíaca e rotacionada cuidadosamente até a cavidade medular. O mandril foi removido e a medula óssea foi aspirada com o auxílio de uma seringa de $20 \mathrm{~m} \ell$, contendo 150UI de heparina ${ }^{\mathrm{f}}$.

A amostra obtida foi preparada de duas maneiras, sendo utilizados 10 coelhos em cada procedimento: 1) medula integral: imediatamente após a coleta de $1 \mathrm{~m} \ell$, a amostra foi cuidadosamente homogeneizada, sendo que, em caso de presença de coágulo, esta foi descartada e foi realizada uma nova coleta; 2) medula centrifugada: imediatamente após a coleta de $2 \mathrm{~m} \ell$, a medula foi colocada em um tubo de centrifugação esterilizado e centrifugada a 1500 rotações por minuto (rpm), por 10 minutos, a temperatura ambiente. $\mathrm{O}$ sobrenadante foi removido e $1 \mathrm{~m} \ell$ do sedimento foi homogeneizado.

As amostras foram submetidas a contagem de células nucleadas, em câmara de Neubauer. Para o cálculo do número de stem cell, foi utilizada a estimativa de uma destas células para 100.000 células nucleadas (CONNOLLY, 1995).

Nos 16 coelhos restantes, para permitir a avaliação da técnica de aplicação da MO, uma falha óssea foi criada cirurgicamente em ambos os rádios. Foi removido um segmento osteoperiosteal de diâmetro completo, com $1,0 \mathrm{~cm}$ de comprimento (cerca de duas a três vezes o diâmetro da diáfise da região), localizado a três centímetros da articulação rádio-carpo-ulnar. A falha óssea foi criada por intermédio de serra elétrica circular $^{\mathrm{g}}$, segundo técnica preconizada por HEIPLE (1963).

Cinco dias após a realização das falhas ósseas, os dezesseis coelhos foram igualmente distribuídos em dois grupos iguais (I e II), novamente anestesiados e preparados para a enxertia percutânea. No grupo I, cada animal recebeu $1,0 \mathrm{~m} \ell$ de medula integral, imediatamente após a coleta, em um dos rádios (tratamento) e $1,0 \mathrm{~m} \ell$ de solução salina fisiológica no rádio contralateral (controle). No grupo II, cada animal recebeu $1,0 \mathrm{~m} \ell$ de medula concentrada em um dos rádios (tratamento) e 1,0m $\ell$ de solução salina fisiológica no rádio contralateral (controle).

Radiografias convencionais obtidas na incidência médio-lateral dos membros operados, realizadas no dia da enxertia e uma semana após, permitiram avaliar as características do crescimento ósseo e eficiência das enxertias.

\section{RESULTADOS E DISCUSSÃO}

A coleta da medula óssea foi simples, dependente de anestesia geral, sendo indispensável heparinizar as seringas, cuja falta resultou em coagulação da amostra e necessidade de nova coleta. Os resultados da contagem celular de aspirados da crista ilíaca de 20 coelhos estão expressos na tabela 1 , sendo que as médias não foram estatisticamente diferentes entre os dois procedimentos, para $p>0,05$.

$\mathrm{O}$ enxerto injetado por via percutânea, nas condições do presente experimento, foi um procedimento simples que teve consideráveis vantagens quando comparado com outros métodos 
Tabela 1 - Contagem de células nucleadas e estimativa de stem cells existentes em um aspirado de $1,0 \mathrm{~m} \ell$ de MO integral imediatamente após a coleta na crista ilíaca de dez coelhos (1 a 10), e após coleta de $2,0 \mathrm{~m} \ell$ de MO, centrifugação e análise em $1 \mathrm{~m} \ell$ do sedimento, em outros 10 coelhos (11 a 20 ).

\begin{tabular}{ccccrr}
\hline Coelho & $\begin{array}{c}\text { Total } \\
\text { Células } / \mathrm{m} \ell\end{array}$ & $\begin{array}{l}\text { Stem } \\
\text { cells }\end{array}$ & Coelhos & \multicolumn{1}{c}{$\begin{array}{c}\text { Total } \\
\text { células/m } \ell\end{array}$} & \multicolumn{1}{c}{$\begin{array}{l}\text { Stem } \\
\text { cells }\end{array}$} \\
\hline 01 & $27,70 \times 10^{6}$ & 277,50 & 11 & $102,10 \times 10^{6}$ & $1.021,00$ \\
02 & $65,00 \times 10^{6}$ & 650,00 & 12 & $91,00 \times 10^{6}$ & 910,00 \\
03 & $68,45 \times 10^{6}$ & 684,50 & 13 & $27,00 \times 10^{6}$ & 270,00 \\
04 & $51,05 \times 10^{6}$ & 510,50 & 14 & $123,90 \times 10^{6}$ & $1.239,00$ \\
05 & $21,25 \times 10^{6}$ & 212,50 & 15 & $43,35 \times 10^{6}$ & 433,50 \\
06 & $61,10 \times 10^{6}$ & 610,10 & 16 & $40,95 \times 10^{6}$ & 409,50 \\
07 & $40,00 \times 10^{6}$ & 400,00 & 17 & $38,40 \times 10^{6}$ & 384,00 \\
08 & $55,10 \times 10^{6}$ & 551,00 & 18 & $67,65 \times 10^{6}$ & 676,50 \\
09 & $41,40 \times 10^{6}$ & 414,00 & 19 & $13,45 \times 10^{6}$ & 134,50 \\
10 & $52,65 \times 10^{6}$ & 526,50 & 20 & $85,15 \times 10^{6}$ & 851,50 \\
Média & $480,9 \times 10^{6}$ & 480,9 & Média & $632,95 \times 10^{6}$ & 632,95 \\
CV & & $31,17 \%$ & & & $57,11 \%$ \\
\hline
\end{tabular}

cirúrgicos de enxertia, rotineiramente utilizados, concordando com as observações de PALEY et al. (1986) de que esta técnica minimiza os riscos de anestesia, infecção e cirurgia. Além disso, a facilidade de coleta e a característica física da medula, que já tinham sido referidas por SHARMA et al. (1992), tornaram viáveis sua utilização com o trauma limitando-se ao sítio de punção e possibilitando a repetição do procedimento, que envolveu os mesmos cuidados de assepsia de qualquer intervenção cirúrgica, à semelhança do que relataram CONNOLLY et al. (1991).

A técnica utilizada para coleta permitiu a obtenção de volumes adequados de medula óssea, conforme citado por vários autores (PALEY et al., 1986; CONNOLLY et al., 1989; MUSCHLER et al.,1997). O êmbolo da seringa não deve ser mantido sob pressão negativa já que a quantidade de sangue que flui para a agulha de aspiração é relevante, o que leva à diluição da amostra, sendo essa condição também observada por CONNOLLY et al. (1991). Ainda, segundo LOKIEC et al., (1996), o aumento na proporção medula/sangue está relacionado à coagulação prematura da amostra. Portanto, quando volumes maiores forem necessários, devem ser realizadas aspirações sucessivas, como recomendaram SALAMA \& WEISSMAN (1978) e em locais espaçados (LOKIEC et al.,1996).

Diversos autores (SALAMA \&

WEISSMAN, 1978; CONNOLLY et al., 1989; HEALEY et al., 1990; TIEDEMAN et al., 1991; MUSCHLER et al., 1997) reconhecem o risco de coagulação da amostra quando não se utiliza heparina, mas não são coincidentes sobre a necessidade, ou maneira de uso da mesma durante a aspiração. Os volumes desse anticoagulante são variados, assim como as formas de uso, existindo o consenso entre esses autores sobre a possibilidade da heparina lesar as células medulares. Da maneira como foi utilizada neste experimento, pode-se considerar que a destruição celular não comprometeu o potencial osteogênico da amostra, o que pode ser confirmado pela reparação da falha do grupo tratamento em relação ao controle (BARROS, 1999). Além disso, deve-se contestar a afirmação de HEALEY et al. (1990) de que não é necessário heparinizar a seringa, devido ao curto espaço de tempo entre os procedimentos de coleta e aplicação, pois a medula por suas características inerentes, possui acentuada capacidade de coagulação. Mesmo porque, deve ser ressaltada a importância da heparinização da MO durante a centrifugação do aspirado.

Quanto à recomendação de PALEY et al. (1986) de que a medula deve ser injetada logo após a aspiração, os resultados desta pesquisa com medula concentrada demonstraram que isto não é imprescindível. Da mesma forma, a afirmação de CONNOLLY et al. (1991) de que a medula coagulada pode ser usada, deve ser repensada pois o processo de coagulação determinando comprometimento da viabilidade celular da amostra, interfere negativamente no potencial osteogênico. Também, o uso de medula coagulada inviabiliza a aplicação por via percutânea, com agulha hipodérmica. Por outro lado, quando foram comparadas a aplicação da medula e da solução salina, ambas tiveram o mesmo grau de dificuldade, que estava relacionado a identificação da falha e ao volume adequado para preenchê-la.

Embora a osteogênese possa ser aumentada pela concentração celular (CONNOLLY et al. 1989) deve-se considerar que nem sempre o maior volume coletado significa maior número de células com capacidade de realizar osteogênese. Conforme relataram MUSCHLER et al. (1997) o número e a concentração das stem cells é influenciado pelo volume aspirado que, por sua vez, é influenciado pela diluição com sangue periférico. A análise dos valores da contagem de células nucleadas (Tabela 1) mostra que, quando o volume do aspirado foi maior, coelhos 11 a 20, a fração da medula óssea que é composta por sangue periférico também aumentou, resultando em diluição de algumas amostras. Porém, na média, o maior volume do aspirado se traduziu em maior número de células derivadas da medula óssea, na amostra que posteriormente foi centrifugada. 
São muitas as variáveis que podem influenciar o número de células obtidas. Cite-se que o número de células nucleadas aumenta se elas estão frouxamente aderidas em um sítio de coleta altamente celular, permitindo que as células da medula óssea no espaço medular fluam para a agulha de aspiração. Por outro lado, o número de células nucleadas diminui se a cavidade medular for hipocelular ou relativamente fibrótica (MUSCHLER et al.,1997).

Em virtude da grande variabilidade de volume utilizado pelos diferentes autores (HEALEY et al., 1990; CONNOLLY et al., 1991; GARG et al., 1993; LOKIEC et al., 1996) e os valores obtidos nesta pesquisa, ficou evidente a dificuldade de se estabelecer um volume ótimo de aspirado para obtenção dos resultados almejados, mas pode-se afirmar que o volume do enxerto de medula óssea a ser usado deve ser definido pela anatomia local, visto que o sucesso da enxertia depende primariamente do número total de células e secundariamente da concentração das mesmas na amostra

Contudo, os dados individuais da contagem celular (Tabela 1) mostram que a concentração celular por centrifugação pode não ser tão benéfica, uma vez que o tempo de preparação aumenta os riscos de contaminação e de que foi observada grande variação individual da contagem celular, que vem sendo confirmada na literatura ao longo dos anos (OWEN, 1980; BURWELL, 1985; CONNOLLY et al., 1989; MUSCHLER et al., 1997).

As figuras 1 e 2 refletem aspectos radiográficos da formação óssea após enxertia percutânea de medula óssea na falha osteoperiosteal em rádio de coelhos.

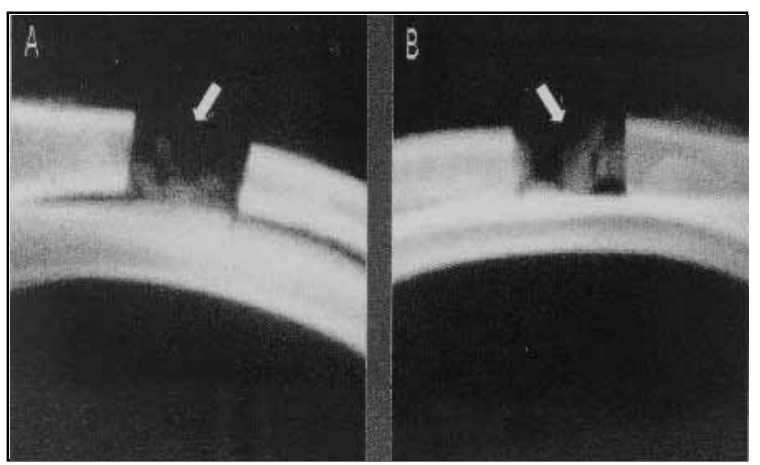

Figura 1 - Aspecto radiográfico da deposição óssea em rádios de coelhos, uma semana após a enxertia da medula. Observam-se regiões circunscritas de radiopacidade dentro da região da falha. A: medula óssea integral e B: medula óssea concentrada.

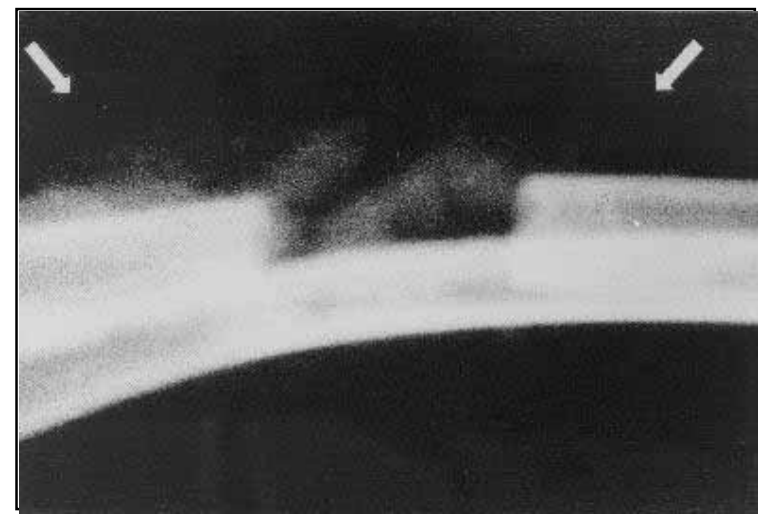

Figura 2 - Demonstração radiográfica da região de enxertia, após uma semana, em um coelho que recebeu medula centrifugada. São observadas regiões circunscritas de radiopacidade na região da falha e no tecido mole adjacente (setas).

Apesar de ter sido observada formação óssea ectópica em apenas um animal do experimento, este risco existe se a injeção ocorre além dos locais de destino (como por exemplo tecido muscular) fato que também foi observado por BURWELL, (1966); PALEY et al. (1986) e CONNOLLY et al. (1989). Essa situação talvez seja mais evidente quando o sítio de enxertia não acomodar suficientemente o material injetado, conforme sugerido por CONNOLLY (1995).

Pela aplicação da medula via percutânea em lesões ósseas, não é introduzido osso desvitalizado, o qual é desvantajoso em determinadas situações clínicas, como por exemplo infecções (PALEY et al., 1986). Deve-se considerar que outros procedimentos de enxertia óssea que necessitam de acesso cirúrgico, causam maior trauma muscular e exposição óssea, o que para HEALEY et al. (1990) aumenta o risco de infecção e interfere na reparação.

As inoculações efetuadas cinco dias após a realização das falhas ósseas foram, inicialmente, para permitir a reparação dos tecidos moles no local evitando-se a saída do enxerto pela ferida cirúrgica, conforme procederam PALEY et al. (1986), SHARMA et al. (1992) e CONNOLLY (1998). Outro motivo foi $o$ fato de se acreditar que a fase inflamatória aguda pode comprometer a viabilidade celular. Contudo, esse período de espera não precisa ser tão extenso como 4 a 12 semanas recomendados por CONNOLLY (1998), em humanos, pois a reação inflamatória local é fenômeno precoce e fugaz.

\section{CONCLUSÕES}

Nas condições desta pesquisa, foi possível chegar a algumas conclusões. Entre elas: na coleta 
da medula óssea, a quantidade de sangue que flui pela agulha é relevante, diluindo a amostra; a contagem celular dos aspirados de medula óssea apresenta ampla variação individual e na média, os aspirados de maior volume apresentaram maior número celular; a concentração das células medulares por centrifugação, a $1500 \mathrm{rpm}$ por 10 minutos, preserva o potencial osteogênico da amostra, e a técnica de aplicação percutânea é simples. Além disso, a característica física da medula facilita a coleta, o trauma ao sítio de punção e a aplicação.

\section{FONTES DE AQUISIÇÃO}

a- Acepran $1 \%$ - Univet - São Paulo.

b - Zoletil - Virbac - São Paulo.

c- Benzetacil - Wyeth - São Paulo.

d- Ração Coelhil "R" - Socil - Belo Horizonte.

e- Agulha Komiyashiki, calibre 12.

f- Heparina. 5.000UI/m $\ell$ - Ariston - São Paulo.

g- Regular double cutting $(22,22 \mathrm{~mm} \mathrm{X} \mathrm{0,6mm)} \mathrm{-} \mathrm{Dentorium.} \mathrm{New}$ York.

\section{REFERÊNCIAS BIBLIOGRÁFICAS}

ASHTON, B. A., ALlen, T. D., HOWLETT, C. R., et al. Distribution of fibroblastic colony-forming cells in rabbit bone marrow and assay of their osteogenic potential by in vivo diffusion chamber method. Calcif Tissue Int, v. 36, p. 83-86, 1984.

BARROS, S.V.S.G. Auto-enxerto percutâneo de medula óssea em falhas segmentares produzidas no rádio de coelhos. Viçosa, MG, 1999. 54p. Dissertação (Mestrado em Medicina Veterinária) - Curso de Pós-graduação em Medicina Veterinária, Universidade Federal de Viçosa, 1999.

BURWELL, R.G. Studies in the transplantation of bone. J Bone Joint Surg, v. 48 B, p. 532-566, 1966.

BURWELL, R.G. The function of bone marrow in the incorporation of a bone graft. Clin Orthop, n. 200, p. 125$141,1985$.

CONNOLLY, J.F., GUSE, R., LIPPIELLO, L., $\boldsymbol{e}$ t $\boldsymbol{a l}$. Development of an osteogenic bone-marrow preparation. J Bone Joint Surg, v. 71 A, n. 5, p. 684-691, 1989.

CONNOLLY, J.F., GUSE, R., TIEDEMAN, J., et al. Autologous marrow injection as a substitute for operative grafting of tibial nonunions. Clin Orthop, n. 266, p. 259-270, 1991.
CONNOLLY, J. F. Injectable bone marrow preparations to stimulate osteogenic repair. Clin Orthop, n. 313, p. 8-18, 1995.

CONNOLLY, J.F. Clinical use of marrow osteoprogenitor cells to stimulate osteogenesis. Clin Orthop, n. 355, p. 257-266, 1998.

GARG, N.K., GAUR, S., SHARMA, S. Percutaneous autogenous bone marrow grafting in 20 cases of ununited fracture. Acta Orthop Scand, v. 64, n. 6, p. 671-672, 1993.

HEALEY, J.H., ZIMMERMAN, P.A., McDONNELL, J.M., et al. Percutaneous bone marrow grafting of delayed union and nonunion in cancer patients. Clin Orthop, n. 256, p. 280285,1990 .

HEIPLE, K.G. A comparative study of the healing process following different types of bone transplantation. J Bone Joint Surg, v. 45 A, p. 1593-1616, 1963.

LOKIEC, F., EZRA, E., KHERMOSH, O., et. al. Simple bone cysts treated by percutaneous autologous marrow grafting. J Bone Joint Surg, v. 78 B, n. 6, p. 934-937, 1996.

MUSCHLER G.V., BOEHM, C., EASLEY, K. Aspiration to obtain osteoblast progenitor cells from human bone marrow: the influence of aspiration volume. J Bone Joint Surg, v. 79 A, n. 11, p. $1699-1709,1997$.

OWEN, M. The origin of bone cells in the postnatal organism. Arthritis Rheum, v. 23, n. 10, p. 1073-1077, 1980.

PALEY, D., YOUNG, M.C., WILEY, A. M., et al. Percutaneous bone marrow grafting of fractures and bony defects. Clin Orthop, n. 208, p. 300-312, 1986.

SALAMA, R., WEISSMAN, S.L. The clinical use of combined xenografts of bone and autologous red marrow. J Bone Joint Surg, v. 60 B, n. 1, p. 111-115, 1978.

SALAMA, R. Xenogeneic bone grafting in humans. Clin Orthop, n. 174, p. 113-121, 1983.

SHARMA, S., GARG, N.K., VELIATH, A.J., $\boldsymbol{e t} \boldsymbol{a l}$. Percutaneous bone-marrow grafting of osteotomies and bony defects in rabbits. Acta Orthop Scand, v. 63, n. 2, p. 166169, 1992.

TIEDEMAN, J.J., CONNOLLY, J.F., STRATES, B.S., et al. Treatment of nonunion by percutaneous injection of bone marrow and demineralized bone matrix an experimental study in dogs. Clin Orthop, n. 268, p. 294-302, 1991. 